\title{
A Brief History of 1-Methylcyclopropene
}

\author{
Michael S. Reid ${ }^{1}$ \\ Department of Plant Sciences, University of California, Mailstop 3, 1 Shields Avenue, Davis, CA 95616 \\ George L. Staby \\ Perishables Research Organization, 18210 Conifer Court, Pioneer, CA 95666
}

\begin{abstract}
Research that led to the discovery of 1-methylcyclopropene (1-MCP) started with efforts to understand the effects of controlled atmosphere storage and continued with studies that examined the nature of the ethylene binding site. Although some researchers focused on the use of silver ion for inhibiting ethylene action, Sisler and his colleagues focused on analogs of olefins that had a similar effect. Efforts to tag the binding site using activation tagging with diazocyclopentadiene led to the discovery of the dramatic effects of cyclopropenes, which were identified as products of its photooxidation. The story is a testament to the value of fundamental research and the collegiality and unique intellectual and technical abilities of the primary inventor, Edward C. Sisler.
\end{abstract}

The brevity of the history of the discovery and commercialization of 1-methylcyclopropene (1-MCP) is a testament to the important physiological effects and commercial use of this compound. However, the story is rooted in the history of modified atmosphere storage. Kidd and West (Kidd and West, 1934; Kidd et al., 1927) showed that low $\mathrm{O}_{2}$ and high $\mathrm{CO}_{2}$ atmospheres inhibited the respiration climacteric and were beneficial for longterm storage of apples. However, it was not until 1962 that Stanley and Ellen Burg demonstrated that the physiological and biochemical basis of these effects was not simply a reduction in respiration, but also an inhibition of the production and action of ethylene (Burg and Burg, 1962). Intrigued by the apparently competitive kinetics of the inhibition of ethylene action by $\mathrm{CO}_{2}$, the Burgs proceeded to use a chemical approach to understanding the nature of the ethylenebinding site (Burg and Burg, 1967). They compared the properties of a range of olefins and other compounds with ethylene-like activity and noted a striking correlation between their activity in inducing ethylene responses and their capacity to accept $\pi$ orbital electrons. Concluding that the ethylene-binding site contained a donor of $\pi$ orbital electrons, they suggested that it was likely to be a transition metal, most probably $\mathrm{Cu}++$.

Although the Burgs were on the track of the ethylene-binding site, they turned their attention to hypobaric storage, a technique that inhibited the effects of ethylene by reducing its partial pressure in plant tissues (Burg, 1967; Burg and Burg, 1966). The story therefore changed little until the mid-1970s when Elmo Beyer at DuPont discovered that low concentrations of $\mathrm{Ag}+$ could inhibit the action of ethylene (Beyer, 1976a). He used a range of model systems in his studies, and a spectacular cover photograph in this journal highlighted the striking effects of $\mathrm{Ag}+$ in preventing ethylene-induced wilting of Cattleya orchid blooms (Beyer, 1976b). Although the discovery of the role of $\mathrm{Ag}+$ in preventing the action of ethylene were very

\footnotetext{
${ }^{1}$ To whom reprint requests should be addressed; e-mailmsreid@ucdavis.edu.
}

exciting, its commercial application was limited because silver, a heavy metal, cannot be applied to edible crops. In addition, $\mathrm{Ag}+$ in the form of silver nitrate is not very mobile in plant vascular systems and Ag+ solutions can cause black spotting of petals and leaves (Halevy and Kofranek, 1976).

The commercial application of silver as an antiethylene treatment was made possible by the discovery by Veen and van de Geijn (1978) that the silver thiosulfate (STS) complex was stable and highly mobile in the vascular system but was still very effective in preventing ethylene action. This finding was quickly exploited in commercial horticulture and led to the development of the famous "super carnations" that helped catapult the Colombian flower industry into prominence worldwide (Reid and Staby, 1980). STS also proved very effective in preventing the effects of ethylene in potted plants and other nursery materials (Cameron and Reid, 1981). STS remains commercially useful today as an Environmental Protection Agency (EPA) -registered material in the United States for preventing the effects of ethylene in cut flowers (www.cdpr.ca.gov/docs/nod/2004$30 . \mathrm{htm}$ ) and is a required pretreatment for certain ethylene-sensitive species marketed through the Dutch flower auctions (www.vbn. nl/en/Images/dianthus_tcm34-13001.pdf).

Although horticulturists were fascinated with silver, Edward Sisler (Fig. 1), an organic chemist in the Biochemistry Department at North Carolina State University, was pursuing a different approach in studies that were initiated because of the interest in using ethylene to accelerate coloring of tobacco leaves in curing sheds (Sisler and Pian, 1973). Following the Burgs' lead, he synthesized numerous olefins and other organic compounds with ethylene-like properties (Sisler and Yang, 1984). To understand the relative effectiveness of these different compounds, he developed a radioactive assay for estimating ethylene binding. Among the compounds that he synthesized was 2,5norbornadiene, which proved to be an effective inhibitor of ethylene action (Sisler et al., 1984). This compound has been a very useful material for physiologists despite its obvious drawbacks; to inhibit ethylene action, plants needed to be continuously exposed to relatively high concentrations of 2,5-norbornadiene, and the gas itself has a foul odor (Robbins et al., 1985).

The breakthrough that led to the development of 1-MCP was the result of an effort to identify the ethylene-binding site protein. Given that 2,5-norbornadiene inhibited ethylene action in a manner that seemed to be competitive, Sisler reasoned that it would be possible to use this compound to identify the ethylene-binding site using activation tagging. This technique had been successfully used to identify enzyme-binding sites by adding the reactive diazo side-chain to the enzyme's substrate or to a competitive inhibitor. After the inhibitor or substrate is bound, the reaction mixture is exposed to ultraviolet light, which causes the diazo group to decompose in a reaction that results in the substrate or inhibitor "tag" being covalently attached to the enzyme protein at a location close to the actual binding domain. If the ligand is radioactively labeled, one can thereby radioactively label the binding site protein as well as amino acid residues close to the active site or binding domain.

Sisler accordingly synthesized a cyclic diolefin with an attached diazo group-diazocyclopentadiene (DACP). However, this highly reactive gaseous molecule did not behave in exactly the fashion that was intended. The activation tag was very effective in inhibiting ethylene action, but the activity only required exposure to fluorescent light, not the expected shorter wavelength ultraviolet (Sisler and Blankenship, 1992, 1993). Moreover (and this was surely the "Ah ha" moment), the gas was effective even if it was exposed to the fluorescent light before being applied to the tissue! DACP certainly was not a commercial product. Highly explosive and toxic, it has to be stored, until needed, dissolved in hexane at $-80{ }^{\circ} \mathrm{C}$. However, it was effective at low concentrations $\left(1 \mu \mathrm{L} \cdot \mathrm{L}^{-1}\right)$ and, unlike 2,5-norbornadiene, was effective as a pretreatment. DACP was soon being widely tested, and articles quickly appeared describing inhibition of ethylene action in a range of model systems and horticultural crops (Blankenship and Sisler, 1993; Sisler and Lallu, 1994). 


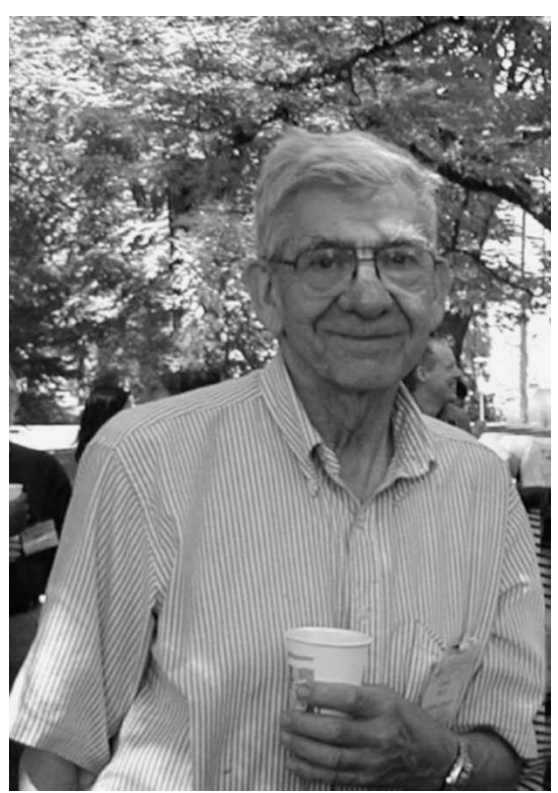

Fig. 1. Ed Sisler at the Postharvest Gordon Research Conference, 2000. Photo courtesy of N. Reid.

Because DACP gas had to be exposed to fluorescent light before it was active, Sisler reasoned that the highly energetic decomposition of DACP released a plethora of breakdown products, one or more of which was presumably the active principle in the irradiated gas. He and his colleagues identified principal components in the gas and, in collaboration with Sylvia Blankenship (Fig. 2 ), discovered that one component, 1-MCP, was an extremely effective inhibitor of ethylene action. Not surprisingly, at this point, the patent attorneys entered the picture! Sisler and Blankenship filed the discovery of 1-MCP (Sisler and Blankenship, 1996), but, characteristically, Sisler freely provided samples of this new compound, which we termed SIS-X, to other researchers. At that time, Margrethe Serek was undertaking postdoctoral studies at UC-Davis with Reid, and she confirmed the remarkable efficacy of the new gas in preventing the deleterious effects of ethylene on ornamentals (Fig. 3; Serek et al., 1994).

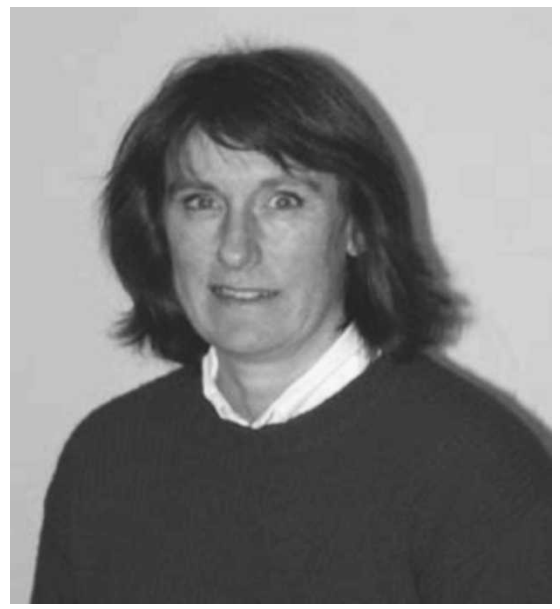

Fig. 2. Sylvia Blankenship, 1-MCP coinventor. Web site photo. <http://www.cals.ncsu.edu/ hort_sci/faculty/blankenship.html>.
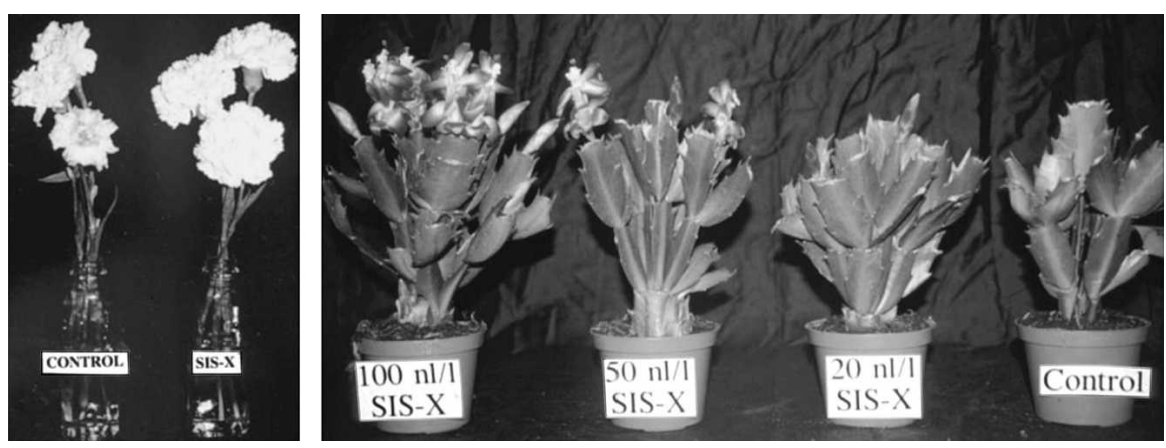

Fig. 3. Early results showing the effectiveness of 1-MCP, then named 'SIS-X', in preventing the natural senescence of carnations (left, photo taken after 1 week in the vase) and Christmas cactus (right, plants treated with $1-\mathrm{MCP}$, then exposed to $1 \mu \mathrm{L} \cdot \mathrm{L}^{-1}$ ethylene.) Photo courtesy of M. Serek.

Filing a patent is one thing, but bringing a product, even one as exciting as $1-\mathrm{MCP}$, to the marketplace is another. Universities these days try to find a potential licensee to underwrite the costs of patenting and registration early in the process. Given the good efficacy data in ornamentals, and the reduced regulatory hurdles involved in registering a growth regulator for use with ornamentals, Sisler sought companies working with the ornamentals industry to license 1-MCP and to finance its further development and registration. At this point, Staby conferred with Sisler and Blankenship and subsequently approached Floralife to see if they might be interested, persuaded them to license 1-MCP for food as well as ornamental crops, and worked with them in accomplishing the product's EPA registration. This process was significantly eased by convincing the EPA that 1-MCP should be classified as a natural or "safer" product, a process that was helped by data that showed its low animal toxicity, its low use rate, the natural occurrence of derivatives (Salaun and Baird, 1995), and structural similarities to the ethylene precursor 1-aminocyclopropane-1-carboxylic acid. A major additional contribution to its commercialization was the development by Jim Daly (Fig. 4) of the powdered cyclodextrin-bound formulation, which provided a convenient way to sell, store, transport, and use 1-MCP (Daly and Kourelis, 2001).

As researchers found more benefits of 1MCP in food crops, Floralife capitalized on the market potential of the product and sold the fruit and vegetable and offshore ornamental rights to Rohm and Haas. Soon thereafter, Rohm and Haas sold their agriculture products portfolio but retained 1-MCP on the strong recommendation of their scientists. There are now hundreds of published articles documenting the many positive (and occasional negative) effects of 1-MCP, but the rest of the story - the effectiveness of 1-MCP for ornamentals, the development of protocols for use with fruits and vegetables, and in particular the success of the product in apple storage - are dealt with by the other articles arising from this colloquium. The ongoing contributions of scientists all over the world make it certain that the science related to 1-MCP will continue to evolve.

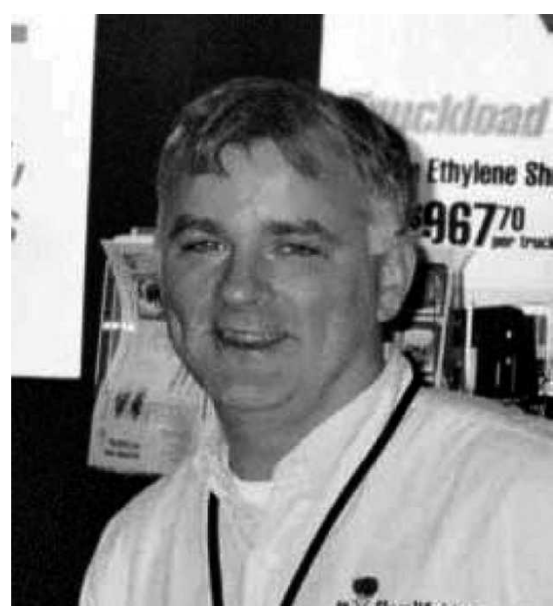

Fig. 4. Floralife's Jim Daly. Web photo. <http:// www.floralife.com $>$.

However, this story is first an inspiring example of the contribution of one scientist, Edward Sisler. Working with limited resources, but possessing singular purpose and unique technical abilities, he demonstrated the lateral thinking and determination that are the essential ingredients of great discoveries and a willingness to collaborate that benefited many of his colleagues.

\section{Literature Cited}

Beyer, E.M. 1976a. A potent inhibitor of ethylene action in plants. Plant Physiol. 58:268-271.

Beyer, E.M. 1976b. Silver ion, a potent antiethylene agent in cucumber and tomato. HortScience 11:195-196.

Blankenship, S.M. and E.C. Sisler. 1993. Response of apples to diazocyclopentadiene inhibition of ethylene binding. Postharvest Biol. Tech. 3: 95-101.

Burg, S.P. 1967. Method for storing fruit. U.S. Patent 3333967.

Burg, S.P. and E.A. Burg. 1962. Role of ethylene in fruit ripening. Plant Physiol. 37:179-189.

Burg, S.P. and E.A. Burg. 1966. Fruit storage at subatmospheric pressures. Science 153:314-315.

Burg, S.P. and E.A. Burg. 1967. Molecular requirements for biological activity of ethylene. Plant Physiol. 42:144-152.

Cameron, A.C. and M.S. Reid. 1981. The use of silver thiosulfate anionic complex as a foliar spray to prevent flower abscission of Zygocactus. HortScience 16:761-762. 
Daly, J. and B. Kourelis. 2001. Synthesis methods, complexes and delivery methods for the safe and convenient storage, transport and application of compounds for inhibiting the ethylene response in plants. U.S. Patent 6313068.

Halevy, A.H. and A.M. Kofranek. 1976. Silver treatment of carnation flowers for reducing ethylene damage and extending longevity. J. Amer. Soc. Hort. Sci. 102:76-77.

Kidd, F. and C. West. 1934. The influence of the composition of the atmosphere upon the incidence of the climacteric in apples. Great Britain Dept. Sci. Ind. Res. Food Invest. Rpt. 1933:119-122.

Kidd, F., C. West, and M.N. West. 1927. Gas storage of fruit. Great Britain Dept. Sci. Ind. Res. Food Invest. Rpt. 30:1-87.

Reid, M.S. and G.L. Staby. 1980. 'Super' carnation solution explained, methods given. Flower News 34:1-19.
Robbins, J.A., M.S. Reid, J.L. Paul, and T.L. Rost. 1985. The effect of ethylene on adventitious root formation in mung bean (Vigna radiata) cuttings. J. Plant Growth Reg. 4: 147-157.

Salaun, J. and M.S. Baird. 1995. Biologically active cyclopropanes and cyclopropenes. Curr. Med. Chem. 2:511-542.

Serek, M., E.C. Sisler, and M.S. Reid. 1994. Novel gaseous ethylene binding inhibitor prevents ethylene effects in potted flowering plants. J. Amer. Soc. Hort. Sci. 119:1230-1233.

Sisler, E.C. and S.M. Blankenship. 1992. Method of counteracting ethylene response by treating plants with diazocyclopentadiene and derivatives thereof. U.S. Patent 5100462.

Sisler, E.C. and S.M. Blankenship. 1993. Diazocyclopentadiene (DACP), a light sensitive reagent for the ethylene receptor in plants. Plant Growth Reg. 12:125-132.
Sisler, E.C. and S.M. Blankenship. 1996. Method of counteracting an ethylene response in plants. U.S. Patent 5518988

Sisler, E.C., R. Goren, and M. Huberman. 1984. Effect of 2,5-norborbadiene on citrus leaf explants. Plant Physiol. Suppl. (Bethesda) 75:127.

Sisler, E.C. and A. Pian. 1973. Effect of ethylene and cyclic olefins on tobacco leaves. Tobacco International 175:27-31.

Sisler, E.C. and S.F. Yang. 1984. Anti-ethylene effects of cis-2-butene and cyclic olefins. Phytochemistry $23: 2765-2768$.

Sisler, E.C. and N. Lallu. 1994. Effect of diazocyclopentadiene (DACP) on tomato fruits harvested at different ripening stages. Postharvest Biol. Technol. 4:245-254.

Veen, H. and S.C. van de Geijn. 1978. Mobility and ionic form of silver as related to the longevity of carnations. Plants 140:93-96. 